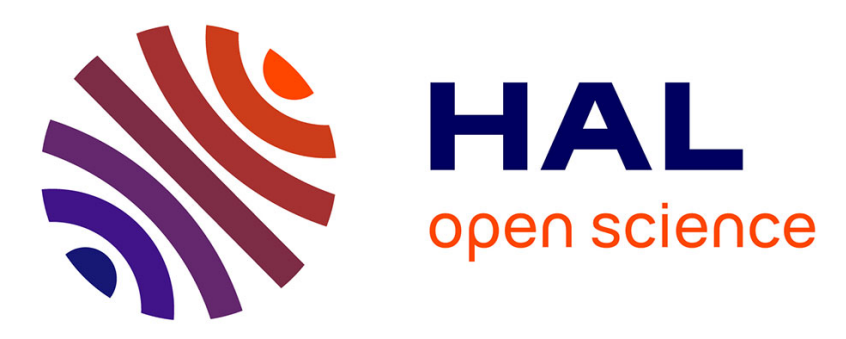

\title{
Prediction of isoelectric point of manganese and cobalt lamellar oxides: application to controlled synthesis of mixed oxides
}

\author{
Céline Tang, Domitille Giaume, Liliane Guerlou-Demourgues, Grégory \\ Lefèvre, Philippe Barboux
}

\section{To cite this version:}

Céline Tang, Domitille Giaume, Liliane Guerlou-Demourgues, Grégory Lefèvre, Philippe Barboux. Prediction of isoelectric point of manganese and cobalt lamellar oxides: application to controlled synthesis of mixed oxides. Langmuir, 2018, 34 (23), pp.6670-6677. 10.1021/acs.langmuir.8b00190 . hal-01828399

\section{HAL Id: hal-01828399 \\ https://hal.science/hal-01828399}

Submitted on 3 Jul 2018

HAL is a multi-disciplinary open access archive for the deposit and dissemination of scientific research documents, whether they are published or not. The documents may come from teaching and research institutions in France or abroad, or from public or private research centers.
L'archive ouverte pluridisciplinaire HAL, est destinée au dépôt et à la diffusion de documents scientifiques de niveau recherche, publiés ou non, émanant des établissements d'enseignement et de recherche français ou étrangers, des laboratoires publics ou privés. 


\title{
Prediction of isoelectric point of manganese and cobalt lamellar oxides: application to controlled synthesis of mixed oxides
}

\author{
Tang C. ${ }^{1,3}$, Giaume D. ${ }^{2,3}$, Guerlou-Demourgues L. ${ }^{1,3}$, Lefèvre G. ${ }^{2}$, Barboux Ph. ${ }^{2,3}$ \\ ${ }^{1}$ CNRS, Univ. Bordeaux, Bordeaux INP, ICMCB, UMR 5026, F-33600 Pessac, France \\ ${ }^{2}$ Chimie-ParisTech, PSL Research University, CNRS Institut de Recherche de Chimie-Paris (IRCP), 75005 Paris, France \\ ${ }^{3}$ RS2E, Réseau Français sur le Stockage Electrochimique de l'Energie, CNRS FR3459 Amiens, 3459, France
}

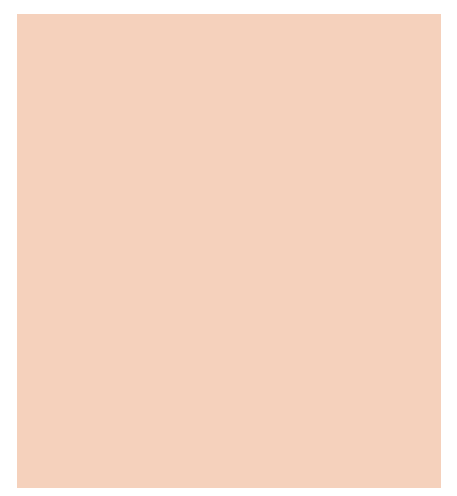

\begin{abstract}
To design novel layered materials, bottom-up strategy is very promising. It consists of (1) synthesizing various layered oxides, (2) exfoliating them, then (3) restacking them in a controlled way. The last step is based on electrostatic interactions between different layered oxides and is difficult to control. The aim of this study is to facilitate this step by predicting the isoelectric point (IEP) of exfoliated materials. The Multisite Complexation model (MUSIC) was used for this objective and was shown to be able to predict IEP from the mean oxidation state of the metal in the (hydr)oxides, as the main parameter. Moreover, the effect of exfoliation on IEP has also been calculated. Starting from platelets with a high basal surface area over total surface area, we show that the exfoliation process has no impact on calculated IEP value, as verified with experiments. Moreover, the restacked materials containing different monometallic (hydr)oxide layers also have an IEP consistent with values calculated with the model. This study proves that MUSIC model is a useful tool to predict IEP of various complex metal oxides and hydroxides.
\end{abstract}




\section{Introduction}

Over the past decade the study of ultrathin 2D materials has evolved into one of the most popular areas of nanomaterials science.(1-3) From graphene(4-6) to chalcogenides, $(7,8)$ nitrides, MXenes,(9) or layered metal oxides,(10) 2D materials present very exciting physical and chemical properties, $(5,8,11)$ explaining their high versatility and opening then to a large field of applications such as electrocatalysis,(12) biomedicine,(13) or energy storage.(9,14-16) To take advantage of the specific properties of different $2 \mathrm{D}$ materials, and thus widen their applications, nanocomposite engineering(17-19) is necessary. Construction of structurally defined functional hybrid materials by using multiple 2D nanosheets as building blocks(20) should allow overcoming the weaknesses of each individual material, while favoring fine-tuning and synergy of their properties. In the field of energy storage, layered oxides as electrode materials are particularly interesting for their high 2D ionic mobility thanks to the interlayer space in which alkaline ions can insert/deinsert, but often suffer from a low electronic conductivity to reach high specific capacitance. $(21,22)$

Among the materials developed as active electrode material, layered $\mathrm{MnO}_{2}$ is one of the most extensively studied for its high specific capacitance (up to $250 \mathrm{~F} \mathrm{~g}(23-25)$ ), good chemical stability, natural abundance, and low toxicity. However, it presents a rather low electronic conductivity $\left(10^{-5}\right.$ to $10^{-6} \mathrm{~S} \mathrm{~cm}^{-1}$ ). Alternatively, layered cobalt (oxyhydr)oxides containing $\mathrm{Co}^{4+}$ ions are proven to exhibit a higher electronic conductivity $\left(10^{-3}\right.$ to $\left.10^{-2} \mathrm{~S} \mathrm{~cm}^{-1}\right)$, which can be considerably boosted by increasing the amount of $\mathrm{Co}^{4+}$ (up to $1 \mathrm{~S} \mathrm{~cm}^{-1}$ ).(26-28) Such materials present lower specific capacitance than their manganese homologues but can be successfully used, for instance, as conducting additive in alkaline batteries.(29)

This work focuses on the combination of both high electronic conductivity of layered cobalt oxyhydroxides, and high pseudocapacity of manganese oxide in one hybrid material. As the two oxides are composed of stacked lamellae, our approach consists first in delaminating the initial oxides into mono- or oligolamellae, and then restacking these monometallic building blocks together, thus combining the properties of each material.

To restack the building blocks, the easiest strategy is to use electrostatic attractions of oppositely charged slabs dispersed in a suspension. This surface charge is the origin of the driving force for a controlled assembly of multiple lamellae, but is dependent on experimental conditions. Determination and prediction of isoelectric point (IEP) is therefore of great importance to reach controlled assembly of oligolamellae and obtain mixed layered oxides. We present here for the first time the application of the Multisite Complexation model (MUSIC) to theoretically predict the IEP of the lamellar units, depending on the mean oxidation state of the transition metals present in the slabs. We show that this model, developed for the determination of monometallic oxide IEP, is also robust even when the restacked materials become more complex, i.e. when nature and oxidation states of the metal ions vary.

\section{Experimental Section}

Material Syntheses : Manganese Oxide Oligolayers : Layered sodium manganese oxide powder is prepared by precipitation of a manganese salt in an alkaline oxidizing solution, following the "classic" route presenting high yield, developed by Ching et al.(30) Typically $10.0 \mathrm{mmol}(1.69 \mathrm{~g}) \mathrm{MnSO}_{4} \cdot \mathrm{H}_{2} \mathrm{O}$ (Sigma-Aldrich) is dissolved in $30 \mathrm{~mL}$ of water in a plastic beaker before rapid addition of a $\mathrm{NaOH}$ solution $(6 \mathrm{M}, 30 \mathrm{~mL})$ under vigorous stirring, leading to a brown suspension. Addition of $\mathrm{K}_{2} \mathrm{~S}_{2} \mathrm{O}_{8}(7.0$ $\mathrm{mmol}, 1.89 \mathrm{~g}$ ) in small packs over a period of $45 \mathrm{~min}$ and under vigorous stirring follows. Stirring for 30 more minutes results in a brown-black slurry, which is subsequently washed with distilled water until the $\mathrm{pH}$ of resulting supernatant is stable and close to 7 . The obtained slurry is finally dried at $60{ }^{\circ} \mathrm{C}$ for $24 \mathrm{~h}$. Subsequent treatment with $0.1 \mathrm{M} \mathrm{HCl}$ solution for 4 days at room temperature produces protonated birnessite manganese oxide, denoted as $\mathrm{H}-\mathrm{MnO}_{2}$. This lamellar phase exhibits the following chemical formula: $\left\{\mathrm{H}_{0.35} \mathrm{Na}_{0.01}\left(\mathrm{H}_{2} \mathrm{O}\right)_{0.44}\right\}_{\text {interslab }}\left\{\mathrm{MnO}_{2}\right\}_{\text {slab. }}$. (31) The exfoliated nanosheets of the layered 
manganese oxide are obtained after suspension of the $\mathrm{H}-\mathrm{MnO}_{2}$ powder in a tetrabutylammonium hydroxide solution (TBAOH, Sigma-Aldrich) in a closed vessel for more than 12 days at room temperature under stirring. The resulting colloidal suspension, denoted as "ex $\mathrm{H}-\mathrm{MnO}_{2}$ " (for "exfoliated $\mathrm{MnO}_{2}{ }^{\prime \prime}$ ) is centrifuged at a speed of $4000 \mathrm{rpm}(3584 \mathrm{~g})$ for $15 \mathrm{~min}$ to remove the fraction of incompletely exfoliated particles (at the bottom of the flask).

Cobalt Oxide Oligolayers : Layered cobalt oxyhydroxide is synthesized by precipitation at room temperature of a cobalt salt in alkaline oxidizing media. Typically, $2.91 \mathrm{~g}(10.0 \mathrm{mmol})$ of $\mathrm{Co}\left(\mathrm{NO}_{3}\right)_{2} \cdot 6 \mathrm{H}_{2} \mathrm{O}$ (Sigma-Aldrich) is dissolved in $300 \mathrm{~mL}$ of distilled water and added dropwise in $\mathrm{NaOH}(2 \mathrm{M}, 11 \mathrm{~mL})$. A solution of $\mathrm{NaClO} 48^{\circ}$ (i.e., $4 \mathrm{M}, 7.5 \mathrm{~mL}$ ) is immediately added, as a strong oxidant, before stirring for 60 $\mathrm{min}$. Thorough rinsing by centrifugation ( 8 times at $4000 \mathrm{rpm}$ for $4 \mathrm{~min}$ ) is performed until the supernatant has reached neutrality. The phase obtained after drying at $60^{\circ} \mathrm{C}$ for $24 \mathrm{~h}$ is denoted as $\mathrm{H}$ $\mathrm{CoO}_{2}$, and exhibits the following general formula: $\left\{\mathrm{H}_{0.86} \mathrm{Na}_{0.06}\left(\mathrm{H}_{2} \mathrm{O}\right)_{0.19}\right\}_{\text {interslab }}\left\{\mathrm{CoO}_{2}\right\}_{\text {slab. }}$ (21) The powder is then suspended in an aqueous solution of $\mathrm{TBAOH}$ for 20 days at room temperature under vigorous stirring to be exfoliated. The colloidal suspension, which is denoted as "ex $\mathrm{H}-\mathrm{CoO}_{2}$ " is then centrifuged at $4000 \mathrm{rpm}$ (3584g) for $15 \mathrm{~min}$ to remove the fraction of incompletely exfoliated particles. Assembly of Oligolayers : The restacking process of the mixed material is performed at a $\mathrm{pH}$ that is carefully chosen between the two IEP of the oligolamellae of the ex $\mathrm{H}-\mathrm{CoO}_{2}$ and ex $\mathrm{H}-\mathrm{MnO}_{2}$ suspensions. Both colloidal suspensions are then brought to $\mathrm{pH} 4.5$ by addition of $\mathrm{HNO}_{3}$. To revert the flocculation process due to high ionic strength, both suspensions are centrifuged at $5000 \mathrm{rpm}(5600 \mathrm{~g})$ for $5 \mathrm{~min}$. Then, in a solution of $\mathrm{HNO}_{3}$ at the same $\mathrm{pH}$, the oligo-layers are resuspended with the help of an ultrasound probe. The two colloidal suspensions are then simultaneously added to $200 \mathrm{~mL}$ of $\mathrm{HNO}_{3}$ at this correct $\mathrm{pH}$ at $1 \mathrm{~mL} / \mathrm{min}$. Flocculation is observed and the precipitate is recovered by centrifugation at $5000 \mathrm{rpm}(5600 \mathrm{~g})$ for $15 \mathrm{~min}$. The phases obtained are dried at $60^{\circ} \mathrm{C}$ for $24 \mathrm{~h}$ before being characterized. By varying the initial material quantities of colloidal suspensions, multiple restacked powders with different Mn/Co ratios have been obtained: 50/50, 75/25, 33/67.

Characterization Methods : A Philips Panalytical X'Pert Pro diffractometer was used to record X-ray powder diffraction patterns. In the case of manganese oxides, a $\mathrm{Cu}$ Ka radiation was used. The powder diffraction patterns were recorded for about $2 \mathrm{~h}$ in the $8^{\circ}-80^{\circ}(2 \theta)$ angular range, with a $0.0167^{\circ}(2 \theta)$ step size and a $2.122^{\circ}(2 \theta)$ active width in the detector. In the case of cobalt oxyhydroxides, a Co Ka radiation was used. The powder diffraction patterns were recorded for about $10 \mathrm{~h}$ in the $10^{\circ}-110^{\circ}(2 \theta)$ angular range, with a $0.0167^{\circ}(2 \theta)$ step size and a $2.122^{\circ}(2 \theta)$ active width in the detector. Chemical analysis was performed by inductively coupled plasma (ICP) for $\mathrm{Mn}, \mathrm{Co}, \mathrm{Li}, \mathrm{Na}, \mathrm{K}$ titration, and by elementary analysis for $\mathrm{H}$ and $\mathrm{C}$ titration. The average oxidation state of cobalt and manganese was determined by the iodometric titration method. TEM pictures were recorded with a JEOL JEM-2200 FS microscope at an accelerating voltage of $200 \mathrm{kV}$. The SEM-EDS pictures were recorded on a JEOL 6700F to provide detailed imaging information. Zeta potentials of suspended materials were recorded on a Malvern Zetasizer while varying $\mathrm{pH}$ and after an equilibration time of $5 \mathrm{~min}$ at each $\mathrm{pH}$.

Modeling Approach : Several approaches have tried to correlate IEP/PZC to characteristics of metal (hydr)oxides. Parks(32) has proposed a formula based on the size and valence $(z)$ of the cation and on the crystal field stabilization energy of the solid for simple (hydr)oxides. Sverjensky and Sahai(33) have developed a model to simulate PZC of complex oxides (including clays) using the dielectric constant of the solid, the bond valence ( $z$ /coordination number), and the metal-oxygen distance.

Because the IEP is a particular point of the function describing the evolution of surface charge vs $\mathrm{pH}$, an indirect possibility to determine its value is to model the whole surface charge curve, i.e. to use a model able to give the characteristics of each acido-basic site present at the surface (site density, charge, acidity constant). This approach has been developed in MUSIC model(34-36) and is briefly described below. An analogy with the protonation constants of hydroxo and oxo complexes has allowed the authors of this model to deduce a linear relation between the acidity constant of a surface site with the number, the valence, and the coordination number of metal cations coordinated to the oxygen atoms.(34) This indicates that the structure of a crystal face exposed to the solution monitors the surface charge of a particle, which can be considered as the sum of the contribution of each face. In a refined theory, the authors have given the following relation $\underline{1}$ to calculate the proton affinity constant, $\log K$, from the 
under-saturation of the oxygen valence of the reactant:

$$
\log K=-A\left(\sum s_{j}+V\right)
$$

In which $V$ is the valence of the oxygen (-2), $A$ is a constant (19.8) obtained by a calibration using dissolved hydroxo and oxo complexes proposed by Hiemstra et al.,(36) and $s_{j}$ represents the bond valence of the surrounding atoms $j$ around oxygen.

The oxygen atom has electrons in the $2 p$ orbitals that can be shared with either metal cations or protons, resulting in covalent or hydrogen bonds. The bond valence will depend on the nature of the surrounding atom:

- The bond valence of the metal can be calculated using Pauling's rule $(z / \mathrm{CN})(37)$ or with the formula proposed by Brown and Altermatt(38) based on the metal-oxygen distance. In the case of a symmetrical charge distribution in the coordination environment, $s_{\mathrm{Me}}$ can be found using Pauling's rule. Because metal ions are in octahedral sites in the oxyhydroxide of this study (further developed below), their charge is distributed over 6 bonds, $s_{\mathrm{Me}}=z / 6$. The overall oxidation state of the metal cations can vary from 2 to 4 , but in no case, can all three be found in the same lamella.

- If one oxygen orbital is occupied by a proton, $s_{\mathrm{H}}=0.8$.

- If one oxygen orbital is occupied by a hydrogen bond between the oxygen atom and a water molecule, $s=\left(1-s_{\mathrm{H}}\right)$.

An overview of the different possible contributions is given in Figure 1 in the case of a surface oxygen, bound to 3 metal ions, protonated once and presenting a hydrogen bond with a water molecule. With these clarifications, the general formula to calculate the proton affinity constant gives eq 2 :

$$
\log K_{i, q}=-A\left(\sum_{j=1}^{i} s_{M e_{j}}+m_{q} s_{H}+n_{q}\left(1-s_{H}\right)+V\right)
$$

Where $i$ is the number of metal cations around the oxygen (maximum 3 ), $m$ is the number of oxygen orbitals occupied by protons, $n$ is the number of free oxygen orbitals that can potentially be occupied by hydrogen bonds, and $q$ is the protonation state of the oxygen (which can be either 1 or 2, as shown in processes 3 and 4 .

Proton affinity is associated with the two protonation processes, process 3 and process 4 .

First protonation:

$$
\left(K_{i, 1}\right) \mathrm{Me}_{i}-\mathrm{O}^{y}+\mathrm{H}^{+} \leftrightarrows \mathrm{Me}_{i}-\mathrm{OH}^{(1+y)}
$$

Second protonation:

$$
\left(K_{i, 2}\right) \mathrm{Me}_{i}-\mathrm{OH}^{(1+y)}+\mathrm{H}^{+} \leftrightarrows \mathrm{Me}_{i}-\mathrm{OH}_{2}^{(2+y)}
$$

The charge of the group, $y$, can be calculated from the bond valence of surrounding metals (Me) by eq 5 : Céline Tang, Domitille Giaume, Liliane Guerlou-Demourgues, Grégory Lefèvre, Philippe Barboux. Prediction of isoelectric point of manganese and cobalt lamellar oxides : application to controlled synthesis of mixed oxides. Langmuir, American Chemical Society, 2018, 34 (23), pp.6670-6677. 


$$
y=-2+\sum_{j=1}^{i} s_{\mathrm{Me}_{j}}
$$

Such charge determination for each site allows the calculation of the surface charge of the whole surface, and thus of the IEP.

This model has thus been used to predict IEP values of the exfoliated lamellae, in order to determine the optimal conditions that are necessary to restack them together. Comparison with experimental values is described in the next section.

\section{Results and Discussion}

Structural Description for the Model : Two layered oxyhydroxides have been used in this work as monometallic pristine materials: birnessite manganese oxide $\mathrm{H}-\mathrm{MnO}_{2}$, which crystallizes in $\mathrm{C} 2 / m$ space group, and beta(III)-cobalt oxyhydroxide $\mathrm{H}-\mathrm{CoO}_{2}$, which crystallizes in $\mathrm{R} \bar{m}$ group. Both materials are composed of layers of $\mathrm{MeO}_{6}$ octahedra $(\mathrm{Me}=\mathrm{Mn}, \mathrm{Co})$ sharing 6 edges with their neighbors. These planar monoslabs can be considered as building blocks. They are separated by an interlamellar space, in which cations such as $\mathrm{H}^{+}, \mathrm{Na}^{+}$, and $\mathrm{K}^{+}$can insert, in order to balance the negative charge of the slabs due to an average oxidation state of manganese or cobalt lower than 4 . The main crystallographic difference lies in the monoslabs arrangement in $\mathrm{H}-\mathrm{MnO}_{2}$, which differs from $\mathrm{H}-\mathrm{CoO}_{2}$. This only impacts the interlamellar site geometry, which can be either prismatic or hexagonal (Figure 2).

This structural arrangement allows to define various oxygen sites, presenting either 1, 2, or 3 bonds with neighboring metal ions as presented in Figure 2. Precisely, oxygens in the core of a lamella are triply coordinated with metal ions, while on the edges of the lamella, the oxygens are either mono- or bicoordinated with metal ions.

The X-ray diffraction patterns of these materials (Figure 3) reveal sharp diffraction (001) peaks for H$\mathrm{MnO}_{2}$, and broader (003) peak for $\mathrm{H}-\mathrm{CoO}_{2}$. The broader peak is explained by shorter monocrystalline coherence length, consistent with the small size of the $\mathrm{H}-\mathrm{CoO}_{2}$ objects (Figure $4 \mathrm{a}$ and $\mathrm{c}$ ). We can thus expect a high crystallinity in the (001) direction for $\mathrm{H}-\mathrm{MnO}_{2}$ platelets, while $\mathrm{H}-\mathrm{CoO}_{2}$ appears less wellcrystallized.

This lamellar crystalline structure favors a morphology of platelets, as presented by SEM images of Figure $4 \mathrm{a}$ and e. These platelets are some micrometers wide for $\mathrm{H}-\mathrm{MnO}_{2}$, while only hundreds of nanometers wide for $\mathrm{H}-\mathrm{CoO}_{2}$. Describing the platelet morphology roughly consists in defining two types of surfaces, a basal plane and lateral faces. The basal area percentage corresponds to the basal surface area over total surface area and has been experimentally determined from measuring basal and lateral surfaces on SEM pictures. The values fall around $86 \%$ for $\mathrm{H}-\mathrm{CoO}_{2}$ and $96 \%$ for $\mathrm{H}-\mathrm{MnO}_{2}$. Surface sites are oxygen sites, which can be protonated in solution depending on the $\mathrm{pH}$ conditions. They are differentiated by the number of their metal neighbors (further explained below).

When inserting $\mathrm{TBA}^{+}$ions in the interlayer space, separation of the sheets occurs due to steric hindrance, thus leading to exfoliation of the materials into oligolayers of a few lamellae (2 to 5), as schematized in Figure 2. As shown on the TEM images of exfoliated materials (Figure 4c and g), the process does not affect the integrity of the slabs. It can therefore be assumed that the slabs still present the same oxygen surface sites. The restacked materials obtained are analyzed by TEM and SEM coupled with EDS and shown in Figure $4 \mathrm{~d}$ and $\mathrm{h}$. The manganese atoms are represented in red, whereas the cobalt ions are represented in green. The TEM-EDS mapping shows that the restacked material presents both Co and $\mathrm{Mn}$ ions with an intimate restacking. Although this technique cannot confirm the presence of alternate Mn-Co monolayers, mixed nanocomposites with domains of few tens of nanometers for each metal 
oxide are successfully observed.

If $\mathrm{pH}$ conditions are such that opposite surface charges are present on the two monometallic exfoliated materials, an alternative assembly of the two monometallic oligolayers occurs by simple mixing the suspensions, leading to one single complex dimetallic material. The knowledge of the surface charge of the exfoliated materials is therefore required to determine the restacking conditions and justifies the development of modeling tools to predict the IEP of each exfoliated material.

Description of Oxygen Sites for the Model : The main hypothesis taken in this model is a perfect solid constituted of stacked layers of $\mathrm{MeO}_{6}$ octaedra sharing 6 edges with their neighbors as in the initial oxyhydroxides, presenting no vacancies nor defects. Indeed, considering the presence of vacancies (explained below) would induce taking into account other hypotheses, when their formation and number are not exactly modeled. This allows a simplification (that is later justified by XPS measurements). Because the geometric arrangement in the slabs of $\mathrm{H}-\mathrm{MnO}_{2}$ and $\mathrm{H}-\mathrm{CoO} 2$ is the same, thus leading to same type of oxygen surface sites, distinction between the oxygen sites in the manganese and the cobalt oxyhydroxides for the model relies on (i) the mean oxidation state of the metal, which differs in the two materials; (ii) the various oxygen site density in the two materials, due to various metal ionic radii and different interlayer space; (iii) the thickness of the particles, as the site densities of various groups on basal face or lateral face differ.

We experimentally determined the mean oxidation state of $\mathrm{Mn}$ and $\mathrm{Co}$ in the $\mathrm{H}-\mathrm{MeO}_{2}(\mathrm{Me}=\mathrm{Mn}, \mathrm{Co})$ phases by different methods. Iodometric titration results in mean oxidation state of $3.00 \pm 0.15$ for Co and $3.60 \pm 0.05$ for Mn.(31) In this type of layered oxides, at least two different oxidation states for metal ions coexist in the layers, which leads to various types of oxygen sites used in the MUSIC model. In the particular case of $\mathrm{Mn}$ oxide, up to three different oxidation states can be found $\left(\mathrm{Mn}^{\mathrm{II}}, \mathrm{Mn}^{\mathrm{III}}\right.$, and $\mathrm{Mn}^{\mathrm{IV}}$ ) due to a disproportionation reaction $\left(2 \mathrm{Mn}^{\mathrm{III}} \leftrightharpoons \mathrm{Mn}^{\mathrm{IV}}+\mathrm{Mn}^{\mathrm{II}}\right)$. The resulting $\mathrm{Mn}^{\mathrm{II}}$ are removed from the material, thus leading to vacancies in the slabs. However, under our synthesis conditions of $\mathrm{H}-\mathrm{MnO}_{2}$, the number of vacancies has been proved to be quite low(39) and does not vary throughout the exfoliation/restacking process, as iodometric results show (variation of oxidation state during protonation from 3.53 to 3.56 for $\mathrm{H}-\mathrm{MnO}_{2}$ ). Therefore, to simplify the model, these vacancies are not considered in this study.

The stability constants are determined by applying eq 2 to each different site.

Protonation reactivity of the surface oxygens is reported in Table 1, based on thermodynamic considerations. For the sake of simplification, only slabs with mixed oxidation state between 3 and 4 are presented. Calculations considering mixed oxidation state between 2 and 3 could be obtained according to the same formula but are not shown here. Tricoordinated oxygen sites are found in the plane of the layers, while mono- and bicoordinated oxygen sites are only present on the lateral faces of the layers (Figure 2). According to the thickness of the platelets, the densities and proportion of oxygen sites will be different, which will certainly impact the IEP. The density of sites $/ \mathrm{nm}^{2}$ on basal and lateral faces is determined with the crystallographic cell deduced from X-ray data: for $\mathrm{H}-\mathrm{MnO}_{2}, 14.49 \mathrm{sites} / \mathrm{nm}^{2}$ on the basal face and 9.76 sites $/ \mathrm{nm}^{2}$ on lateral face; for $\mathrm{H}-\mathrm{CoO}_{2}, 14.21$ sites $/ \mathrm{nm}^{2}$ and 15.56 sites $/ \mathrm{nm}^{2}$, respectively.

Prediction of Isoelectric Points (IEPs) : On the basis of the model described in the first section and the values obtained for the proton affinity constants, it is possible to predict the isoelectric point (IEP) of the particles. For this purpose, the total surface charge of the particle as a function of $\mathrm{pH}$ has been calculated, and the point of zero charge has been assumed to be equal to the IEP.(35) A Basic Stern Model has been chosen to represent the electrostatic double layer. Two main elements are to be taken into account for the theoretical calculations of IEP: the mean oxidation state of the metal ions, and the proportion of each type of oxygen site, which depends on the grain thickness as previously discussed. The mean oxidation states considered vary from 2 to 4 , as the layered structure is chemically stable only in this range. The basal area percentage over total surface is varied from 50\% (isotropic grains) to $100 \%$ (infinite sheets). The choice of these extremes is justified: (i) the case of an infinite lamella (basal area percentage of $100 \%$ ) defines the planar face IEP; (ii) the case of an isotropic morphology for which lateral and basal area are identical (basal area percentage of 50\%). In this case, we can not give the IEP value of edge faces, as it is mixed with the basal IEP value. However, as our initial platelets already present high Céline Tang, Domitille Giaume, Liliane Guerlou-Demourgues, Grégory Lefèvre, Philippe Barboux. Prediction of isoelectric point of manganese and cobalt lamellar oxides : application to controlled synthesis of mixed oxides. Langmuir, American Chemical Society, 2018, 34 (23), pp.6670-6677. _ $\underline{10.1021 / a c s . l a n g m u i r .8 b 00190\rangle} \cdot \underline{\langle\text { hal-01828399 }}$ 
basal area percentage of $86 \%$ and $96 \%$, this comparison seems to us more relevant. Figure 5 presents the theoretical IEP calculations depending on these two parameters.

MUSIC model predicts a major impact of the mean oxidation state of the metal ions on the IEP value that varies over a $\mathrm{pH}$ range of more than 10 units, which is a well-known phenomenon. But the model also shows an effect of particle morphology on IEP, with an IEP decrease of approximately $3 \mathrm{pH}$ units when moving from thick particles to lamellae. This trend reveals a higher proton affinity of the lesscoordinated oxygen sites, only present on the lateral faces in our model. This morphology impact over IEP is of wide importance for our building block approach, as successful exfoliation will affect the IEP by imposing a basal area percentage close to $100 \%$. Exfoliation of thick materials will thus strongly decrease their IEP (Figure 5). On the contrary, for initial materials which already present a strong morphologic anisotropy (platelet morphology), the impact of the exfoliation on IEP is expected to be more limited. Moreover, for all morphologies of materials, the IEP curve presents some plateaus at specific $\mathrm{pH}$, which are directly linked to $\mathrm{p} K_{\mathrm{a}}$ of oxygen sites (equal to the opposite of the constant of protonation given in Table 1). Plateaus observed are consistent with the usual buffer effect around $\mathrm{p} K_{\mathrm{a}}$ values during acid/base titration.

First, to validate the use of the MUSIC model for the IEP calculation, the experimental IEP values depending on the mean oxidation state of the metal ions are compared with the calculated ones, for basal area percentages comprised between $85 \%$ and $100 \%$ (shaded area in Figure 6).

In Figure 6, the filled circles and squares represent the IEP values of the pristine materials whereas the empty ones correspond to the exfoliated samples. Experimental IEP values of manganese (oxyhydr)oxides are very close to the values calculated for basal area percentage of 100 . The experimental IEP values of cobalt oxyhydroxide samples follow the same trend. Variations of IEP for a same oxidation state are thought to come from variations in initial morphology of the particles, as objects are quite polydisperse. Considering the very good accordance between experimental and calculated values, we think that MUSIC model can accurately predict the experimental IEP values of metal (oxyhydr)oxides, considering only the mean metal oxidation state.

Exfoliation leads to the formation of oligolayers of (oxyhydr)oxides starting from the thicker lamellar materials. As this process should increase the mean basal area percentage to $100 \%$, a decrease of the IEP is expected. However, since the initial basal area percentage is already quite high (85\%), the model predicts a very limited impact of the exfoliation on IEP values of less than 0.5 . Moreover, after exfoliation of the pristine materials, mean oxidation states of both metals have been experimentally determined by iodometric titration, and show that the exfoliation process slightly decreases the mean oxidation state of each metal ion, which should lead to a slight increase of the IEP value. These two effects counterbalanced each other, as observed on Figure 6, on which exfoliated materials present IEP values (empty circles and squares) similar to pristine materials.

Therefore, as the IEP for the exfoliated material and for the pristine material are very close, it is reasonable to consider the pristine material's IEP in order to choose a suitable $\mathrm{pH}$ at which one exfoliated material is positively charged, while the other is negatively charged. This $\mathrm{pH}$ stands around 4-4.5 in our case, for which manganese oxyhydroxide lamellae are negatively charged, while cobalt ones are positively charged. The colloidal suspensions are then added together to obtain restacked materials. Restacked materials with different ratios of Mn:Co have been experimentally obtained, and the global oxidation state of the metals is estimated as a linear combination of $\mathrm{Mn}$ and Co initial oxidation states. IEPs have been measured, and their variations with the mean metal oxidation state are displayed in Figure 7. Note that the sample with the lowest oxidation state (close to 3) corresponds to a restacked material with the highest amount of $\mathrm{Co}$, whereas the samples with higher oxidation states correspond to a higher content of Mn.

We observe a very good agreement between the experimental IEP obtained for various restacked materials with different Mn:Co ratios, and the theoretical curve obtained with MUSIC model. Determination of the effective oxidation state of surface metal ions in restacked materials (required for the application of MUSIC model) has been conducted by XPS measurements (Supporting Information SI.2). Comparisons between the spectra obtained on restacked materials and pristine ones lead to the conclusion that the local bonding environment of $\mathrm{Mn}$ and Co atoms in pristine materials is quasi-identical to that of the restacked 
materials. These results show that restacking occurs without any redox reaction between the different metal ions.(31) Therefore, the exfoliation/restacking process does not modify the mean oxidation state of Mn nor Co on the surface of the materials. This also proves the invariant number of vacancies present in the solid, thus justifying the use of a model presenting no defects. As IEP values are overlapping the shaded area, we can thus conclude that restacked materials still present a high basal area percentage, and that they are composed of both Mn and Co (hydr)oxide layers, which both play a role in the IEP determination.

\section{Summary and conclusion}

To design novel layered materials, we have focused on a bottom-up strategy which consists of synthesizing various layered oxides, exfoliating them, and restacking them together. The restacking process can be especially difficult, since it relies on an electrostatic attraction between the particles. The aim of this study was to facilitate this step by predicting the surface charge (or zeta potential) and determining the IEP of exfoliated materials. The MUSIC model allowed characterization of the effect of exfoliation on charge surface of the particles. Starting from platelets with a high basal area percentage, exfoliation process has no impact on IEP value, as verified by experimental values. The main parameter to take into account is the mean oxidation state of the metal oxide. This means that it is sufficient to know the mean oxidation state of initial particles to predict the IEP, and thus determine a suitable $\mathrm{pH}$ for the restacking. Moreover, the restacked materials (of different ratios) also have an IEP predictable by the model, thus confirming the valid approach of the model. Because the model was first developed on iron oxides and was verified for an accurate prediction of manganese and cobalt oxides, is it is reasonable to think that it can be extended to other various oxides and hydroxides.

\section{Supporting information}

The Supporting Information is available free of charge on the ACS Publications website at DOI: $\underline{10.1021 / \text { acs.langmuir.8b00190. }}$.

\section{Author contributions}

The manuscript was written through contributions of all authors. All authors have given approval to the final version of the manuscript. This work has been partially funded by the RS2E, CNRS. The authors declare no competing financial interest.

\section{Funding}

This work has been partially funded by the RS2E, CNRS.

\section{References}

1. Tan, C.; Cao, X.; Wu, X.-J.; He, Q.; Yang, J.; Zhang, X.; Chen, J.; Zhao, W.; Han, S.; Nam, G.-H. Recent Advances in Ultrathin Two-Dimensional Nanomaterials. Chem. Rev. 2017, 117 (9), 6225- 6331, DOI: 10.1021/acs.chemrev.6b00558

2. Gupta, A.; Sakthivel, T.; Seal, S. Recent Development in 2D Materials beyond Graphene. Prog. Mater. Sci. 2015, 73, 44- 126, DOI: 10.1016/j.pmatsci.2015.02.002

3. Butler, S. Z.; Hollen, S. M.; Cao, L.; Cui, Y.; Gupta, J. A.; Gutiérrez, H. R.; Heinz, T. F.; Hong, S. S.; Huang, 
J.; Ismach, A. F. Progress, Challenges, and Opportunities in Two-Dimensional Materials Beyond Graphene. ACS Nano 2013, 7 (4), 2898- 2926, DOI: 10.1021/nn400280c

4. Geim, A. K.; Novoselov, K. S. The Rise of Graphene. Nat. Mater. 2007, 6, 183, DOI: 10.1038/nmat1849

5. Castro Neto, A. H.; Guinea, F.; Peres, N. M. R.; Novoselov, K. S.; Geim, A. K. The Electronic Properties of Graphene. Rev. Mod. Phys. 2009, 81 (1), 109- 162, DOI: 10.1103/RevModPhys.81.109

6. Geim, A. K. Graphene: Status and Prospects. Science 2009, 324 (5934), 1530- 1534, DOI: 10.1126/science. 1158877

7. Tan, C.; Zhang, H. Two-Dimensional Transition Metal Dichalcogenide Nanosheet-Based Composites. Chem. Soc. Rev. 2015, 44 (9), 2713- 2731, DOI: 10.1039/C4CS00182F

8. Chhowalla, M.; Shin, H. S.; Eda, G.; Li, L.-J.; Loh, K. P.; Zhang, H. The Chemistry of Two-Dimensional Layered Transition Metal Dichalcogenide Nanosheets. Nat. Chem. 2013, 5 (4), 263- 275, DOI: 10.1038/nchem.1589

9. Anasori, B.; Lukatskaya, M. R.; Gogotsi, Y. 2D Metal Carbides and Nitrides (MXenes) for Energy Storage. Nat. Rev. Mater. 2017, 2, 16098, DOI: 10.1038/natrevmats.2016.98

10. Mas-Ballesté, R.; Gómez-Navarro, C.; Gómez-Herrero, J.; Zamora, F. 2D Materials: To Graphene and Beyond. Nanoscale 2011, 3 (1), 20- 30, DOI: 10.1039/C0NR00323A

11. Lv, R.; Robinson, J. A.; Schaak, R. E.; Sun, D.; Sun, Y.; Mallouk, T. E.; Terrones, M. Transition Metal Dichalcogenides and beyond: Synthesis, Properties, and Applications of Single- and Few-Layer Nanosheets. Acc. Chem. Res. 2015, 48 (1), 56- 64, DOI: 10.1021/ar5002846

12. Huang, X.; Zeng, Z.; Bao, S.; Wang, M.; Qi, X.; Fan, Z.; Zhang, H. Solution-Phase Epitaxial Growth of Noble Metal Nanostructures on Dispersible Single-Layer Molybdenum Disulfide Nanosheets. Nat. Commun. 2013, 4, 1444, DOI: $10.1038 /$ ncomms 2472

13. Cheng, L.; Liu, J.; Gu, X.; Gong, H.; Shi, X.; Liu, T.; Wang, C.; Wang, X.; Liu, G.; Xing, H. PEGylated WS(2) Nanosheets as a Multifunctional Theranostic Agent for in Vivo Dual-Modal CT/Photoacoustic Imaging Guided Photothermal Therapy. Adv. Mater. 2014, 26 (12), 1886- 1893, DOI: 10.1002/adma.201304497

14. Zhu, C.; Mu, X.; van Aken, P. A.; Yu, Y.; Maier, J. Single-Layered Ultrasmall Nanoplates of MoS2 Embedded in Carbon Nanofibers with Excellent Electrochemical Performance for Lithium and Sodium Storage. Angew. Chem., Int. Ed. 2014, 53 (8), 2152- 2156, DOI: 10.1002/anie.201308354

15. Muller, G. A.; Cook, J. B.; Kim, H.-S.; Tolbert, S. H.; Dunn, B. High Performance Pseudocapacitor Based on 2D Layered Metal Chalcogenide Nanocrystals. Nano Lett. 2015, 15 (3), 1911- 1917, DOI: 10.1021/nl504764m

16. Tiwari, J. N.; Tiwari, R. N.; Kim, K. S. Zero-Dimensional, One-Dimensional, Two-Dimensional and ThreeDimensional Nanostructured Materials for Advanced Electrochemical Energy Devices. Prog. Mater. Sci. 2012, 57 (4), 724- 803, DOI: 10.1016/j.pmatsci.2011.08.003

17. Zhi, M.; Xiang, C.; Li, J.; Li, M.; Wu, N. Nanostructured Carbon-metal Oxide Composite Electrodes for Supercapacitors: A Review. Nanoscale 2013, 5 (1), 72- 88, DOI: 10.1039/C2NR32040A

18. Zhang, K.; Han, X.; Hu, Z.; Zhang, X.; Tao, Z.; Chen, J. Nanostructured Mn-Based Oxides for Electrochemical Energy Storage and Conversion. Chem. Soc. Rev. 2015, 44 (3), 699- 728, DOI: 10.1039/C4CS00218K

19. Wang, J.-G.; Kang, F.; Wei, B. Engineering of MnO2-Based Nanocomposites for High-Performance Supercapacitors. Prog. Mater. Sci. 2015, 74, 51- 124, DOI: 10.1016/j.pmatsci.2015.04.003

20. Schneiderová, B.; Demel, J.; Pleštil, J.; Janda, P.; Bohuslav, J.; Ihiawakrim, D.; Ersen, O.; Rogez, G.; Lang, K. Nickel Hydroxide Ultrathin Nanosheets as Building Blocks for Electrochemically Active Layers. J. Mater. Chem. A 2013, 1 (37), 11429- 11437, DOI: 10.1039/c3ta12129a

21. Forano, C.; Hibino, T.; Leroux, F.; Taviot-Guého, C. Layered Double Hydroxides. In Developments in Clay Science; Elsevier, 2006; Vol. 1, Chapter 13.1, pp 1021- 1095.

22. Delmas, C.; Fouassier, C.; Hagenmuller, P. Structural Classification and Properties of the Layered Oxides. Physica B+C 1980, 99 (1-4), 81- 85, DOI: 10.1016/0378-4363(80)90214-4

23. Brousse, T.; Toupin, M.; Dugas, R.; Athouël, L.; Crosnier, O.; Bélanger, D. Crystalline MnO2 as Possible Alternatives to Amorphous Compounds in Electrochemical Supercapacitors. J. Electrochem. Soc. 2006, 153 (12), A2171- A2180, DOI: 10.1149/1.2352197

24. Khomenko, V.; Raymundo-Piñero, E.; Frackowiak, E.; Béguin, F. High-Voltage Asymmetric Supercapacitors Operating in Aqueous Electrolyte. Appl. Phys. A: Mater. Sci. Process. 2006, 82 (4), 567- 573, DOI: $10.1007 / \mathrm{s} 00339-005-3397-8$

25. Huang, M.; Li, F.; Dong, F.; Zhang, Y. X.; Zhang, L. L. MnO 2-Based Nanostructures for High-Performance Supercapacitors. J. Mater. Chem. A 2015, 3 (43), 21380- 21423, DOI: 10.1039/C5TA05523G

26. Shaju, K. M.; Guerlou-Demourgues, L.; Godillot, G.; Weill, F.; Delmas, C. Strategies for Synthesizing Conductive Spinel Cobalt Oxide Nanoparticles for Energy Storage Applications. J. Electrochem. Soc. 2012,

Céline Tang, Domitille Giaume, Liliane Guerlou-Demourgues, Grégory Lefèvre, Philippe Barboux. Prediction of isoelectric point of manganese and cobalt lamellar oxides : application to controlled synthesis of mixed oxides. Langmuir, American Chemical Society, 2018, 34 (23), pp.6670-6677. __ $\underline{10.1021 / a c s . l a n g m u i r .8 b 00190\rangle} \cdot \underline{\langle\text { hal-01828399 }}$ 
159 (12), A1934- A1940, DOI: 10.1149/2.036212jes

27. Godillot, G.; Guerlou-Demourgues, L.; Taberna, P.-L.; Simon, P.; Delmas, C. Original Conductive NanoCo3O4 Investigated as Electrode Material for Hybrid Supercapacitors. Electrochem. Solid-State Lett. 2011, 14 (10), A139- A142, DOI: 10.1149/1.3609259

28. Douin, M.; Guerlou-Demourgues, L.; Ménétrier, M.; Bekaert, E.; Goubault, L.; Bernard, P.; Delmas, C. Effect of Thermal Treatment on the Electronic Conductivity Properties of Cobalt Spinel Phases Synthesized by Electro-Oxidation in Ternary Alkaline Electrolyte (KOH, $\mathrm{LiOH}, \mathrm{NaOH})$. Chem. Mater. 2008, 20 (21), 6880- 6888, DOI: 10.1021/cm801775g

29. Tronel, F.; Guerlou-Demourgues, L.; Basterreix, M.; Delmas, C. The Na0.60CoO2 Phase, a Potential Conductive Additive for the Positive Electrode of Ni-MH Cells. J. Power Sources 2006, 158 (1), 722- 729, DOI: 10.1016/j.jpowsour.2005.07.091

30. Ching, S.; Neupane, R. P.; Gray, T. P. Synthesis and Characterization of a Layered Manganese Oxide: Materials Chemistry for the Inorganic or Instrumental Methods Lab. J. Chem. Educ. 2006, 83 (11), 1674, DOI: 10.1021/ed083p1674

31. Tang, C. Exfoliation and restacking of manganese and cobalt based lamellar oxides for supercapacitor electrodes. Material chemistry. Université de Bordeaux, 2017; NNT 2017BORD0789.

32. Parks, G. A. The Isoelectric Points of Solid Oxides, Solid Hydroxides, and Aqueous Hydroxo Complex Systems. Chem. Rev. 1965, 65 (2), 177-198, DOI: 10.1021/cr60234a002

33. Sverjensky, D. A.; Sahai, N. Theoretical Prediction of Single-Site Enthalpies of Surface Protonation for Oxides and Silicates in Water. Geochim. Cosmochim. Acta 1998, 62 (23), 3703- 3716, DOI: 10.1016/S00167037(98)00262-2

34. Hiemstra, T.; De Wit, J. C. M .; Van Riemsdijk, W. H. Multisite Proton Adsorption Modeling at the Solid/Solution Interface of (Hydr)Oxides: A New Approach. J. Colloid Interface Sci. 1989, 133 (1), 105- 117, DOI: 10.1016/0021-9797(89)90285-3

35. Hiemstra, T.; Van Riemsdijk, W. H. A Surface Structural Approach to Ion Adsorption: The Charge Distribution (CD) Model. J. Colloid Interface Sci. 1996, 179 (2), 488- 508, DOI: 10.1006/jcis.1996.0242

36. Hiemstra, T.; Venema, P.; Van Riemsdijk, W. H. Intrinsic Proton Affinity of Reactive Surface Groups of Metal (Hydr) Oxides: The Bond Valence Principle. J. Colloid Interface Sci. 1996, 184 (2), 680- 692, DOI: 10.1006/jcis.1996.0666

37. Pauling, L. The Principles Determining the Structure of Complex Ionic Crystals. J. Am. Chem. Soc. 1929, 51 (4), 1010- 1026, DOI: 10.1021/ja01379a006

38. Brown, I. D.; Altermatt, D. Bond-Valence Parameters Obtained from a Systematic Analysis of the Inorganic Crystal Structure Database. Acta Crystallogr., Sect. B: Struct. Sci. 1985, 41 (4), 244- 247, DOI:

39. Gaillot, A. C. Caractérisation structurale de la birnessite: Influence du protocole de synthèse. Géologie appliquée. Université Joseph-Fourier - Grenoble I, 2002. 


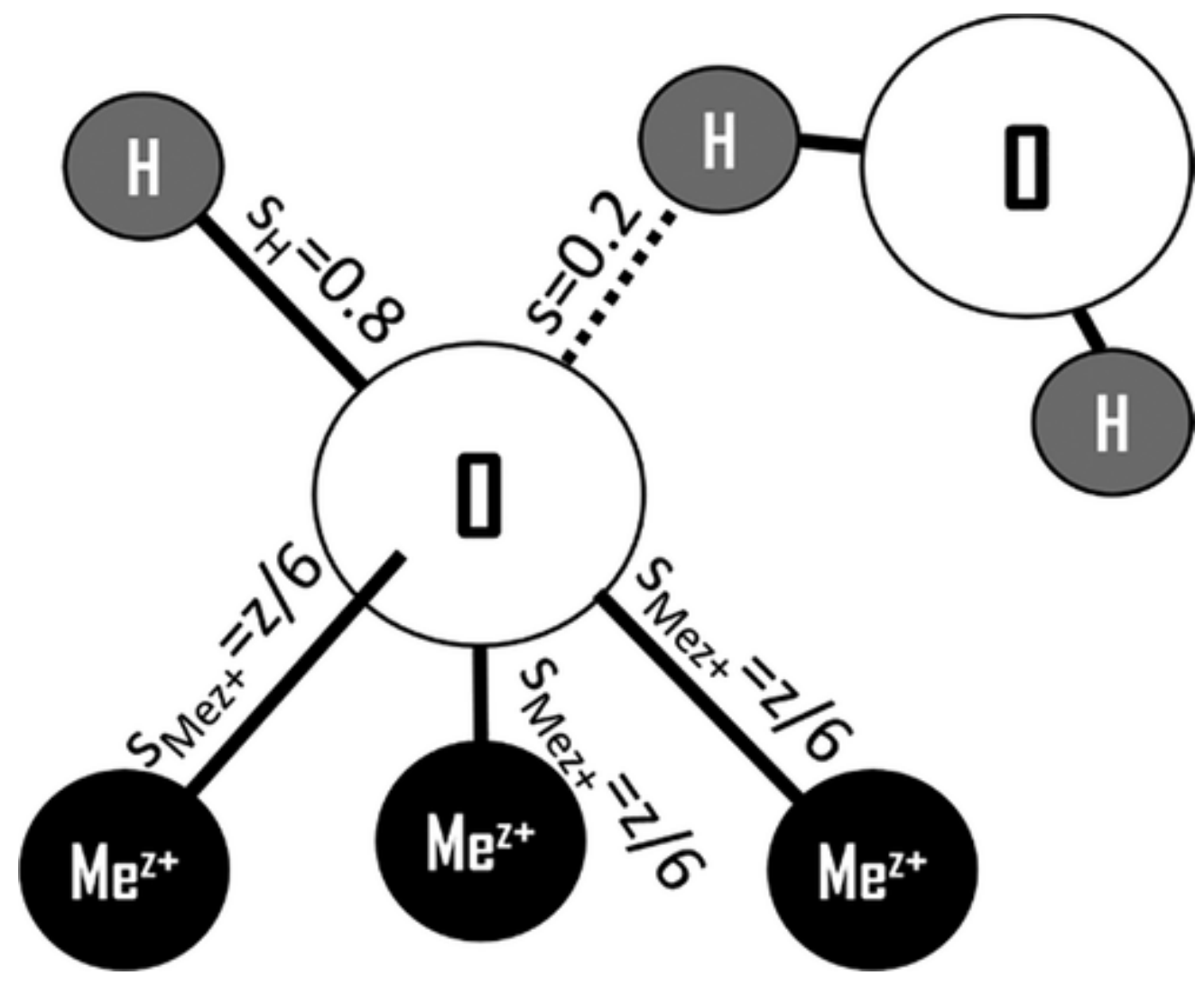

Figure 1. Overview of the different possible contributions of neighbors of a surface oxygen for the calculation of the proton affinity constant. Metal ions contribution is given, proton covalently bound to the oxygen, and water contribution due to hydrogen bond.

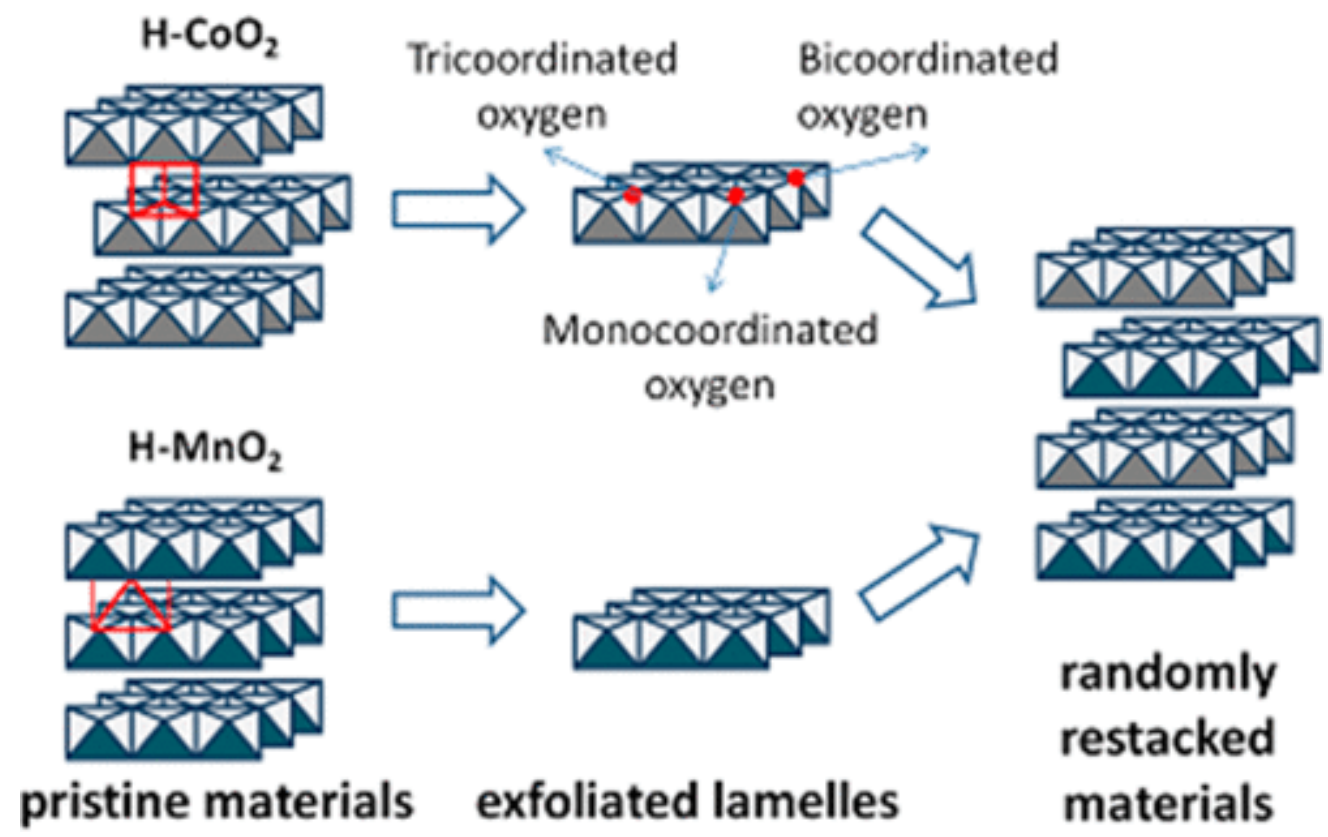

Figure 2. Evolution of the pristine layered material structure during the exfoliation and restacking process. The various oxygen sites are reported as red dots. Mono-, bi-, or tricoordinated oxygen refer to the number of metal neighbors of the surface oxygen site. Environment in the interlayer space is schematized in red. 


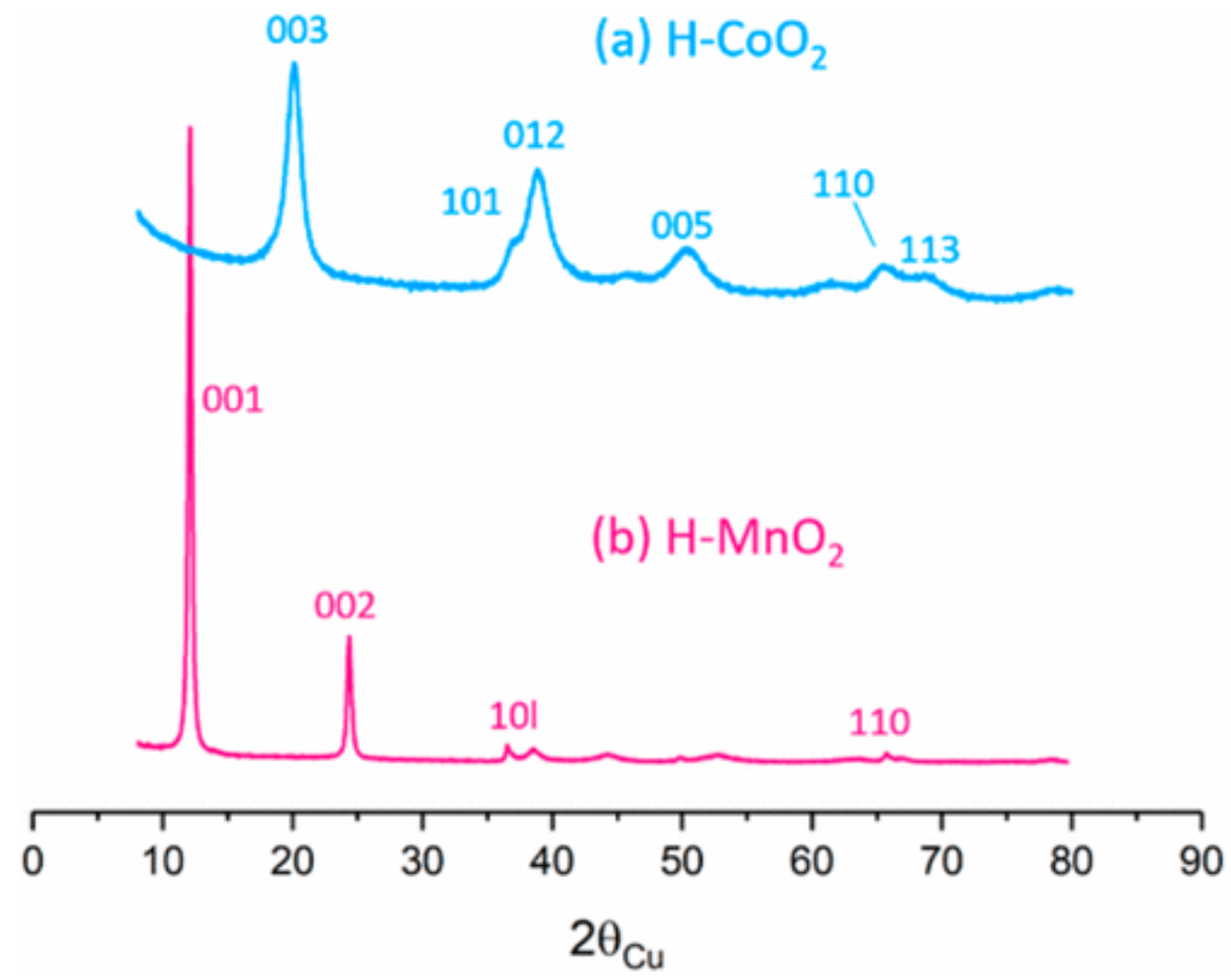

Figure 3. X-ray diffraction patterns of (a) pristine $\mathrm{H}-\mathrm{CoO}_{2}$ and (b) pristine $\mathrm{H}-\mathrm{MnO}_{2}$.

Table 1. Log Stability Constants of the Different Protonation Reactions Considered in the Model

\begin{tabular}{|c|c|c|c|c|}
\hline reaction & \multicolumn{4}{|c|}{ Log stability constant } \\
\hline tridentate variable charge site $^{a}$ & site $\mathrm{Me}^{\mathrm{III}}, \mathrm{Me}^{\mathrm{III}}, \mathrm{Me}^{\mathrm{III} b}$ & site $\mathrm{Me}^{\mathrm{III}}, \mathrm{Me}^{\mathrm{III}}, \mathrm{Me}^{\mathrm{IV} b}$ & site $\mathrm{Me}^{\mathrm{III}}, \mathrm{Me}^{\mathrm{IV}}, \mathrm{Me}^{\mathrm{IV} b}$ & site $\mathrm{Me}^{\mathrm{IV}}, \mathrm{Me}^{\mathrm{IV}}, \mathrm{Me}^{\mathrm{IV} b}$ \\
\hline $\mathrm{Me}_{3} \mathrm{O}^{y}+\mathrm{H}^{+}(\mathrm{aq})=\mathrm{Me}_{3} \mathrm{OH}^{(1+y)}$ & $5.94 \quad Y=-0.5$ & $2.64 \quad Y=-0.33$ & $-0.66 \quad Y=-0.16$ & $-3.96 \quad Y=0$ \\
\hline $\mathrm{Me}_{3} \mathrm{OH}^{(1+y)}+\mathrm{H}^{+}(\mathrm{aq})=\mathrm{Me}_{3} \mathrm{OH}_{2}^{(2+y)}$ & -5.94 & -9.24 & -12.54 & -15.84 \\
\hline bidentate variable charge sites ${ }^{a}$ & site $\mathrm{Me}^{\mathrm{III}}, \mathrm{Me}^{\mathrm{III} b}$ & site $\mathrm{Me}^{\mathrm{III}}, \mathrm{Me}^{\mathrm{IV} b}$ & site $\mathrm{Me}^{\mathrm{IV}}, \mathrm{Me}^{\mathrm{IV} b}$ & \\
\hline $\mathrm{Me}_{2} \mathrm{O}^{y}+\mathrm{H}^{+}(\mathrm{aq})=\mathrm{Me}_{2} \mathrm{OH}^{(1+y)}$ & $15.84 \quad Y=-1$ & $12.54 \quad Y=-0.83$ & $9.24 \quad Y=0.66$ & \\
\hline $\mathrm{Me}_{2} \mathrm{OH}^{(1+y)}+\mathrm{H}^{+}(\mathrm{aq})=\mathrm{Me}_{2} \mathrm{OH}_{2}^{(2+y)}$ & 3.96 & 0.66 & -2.64 & \\
\hline monodentate variable charge sites $^{a}$ & site $\mathrm{Me}^{\mathrm{III} b}$ & site $\mathrm{Me}^{\mathrm{IV} b}$ & & \\
\hline $\mathrm{Me}_{1} \mathrm{O}^{y}+\mathrm{H}^{+}(\mathrm{aq})=\mathrm{Me}_{1} \mathrm{OH}^{(1+y)}$ & $21.78 \quad Y=-1.5$ & $18.48 \quad Y=-1.33$ & & \\
\hline $\mathrm{Me}_{1} \mathrm{OH}^{(1+y)}+\mathrm{H}^{+}(\mathrm{aq})=\mathrm{Me}_{1} \mathrm{OH}_{2}^{(2+y)}$ & 9.9 & 6.6 & & \\
\hline
\end{tabular}

${ }^{a}$ Oxygen sites are differentiated by their bond to 1,2 , or 3 metals and called mono-, bi-, or tricoordinated sites. ${ }^{b}$ The oxidation state of each neighboring metal is reported, as it influences the stability constants. 


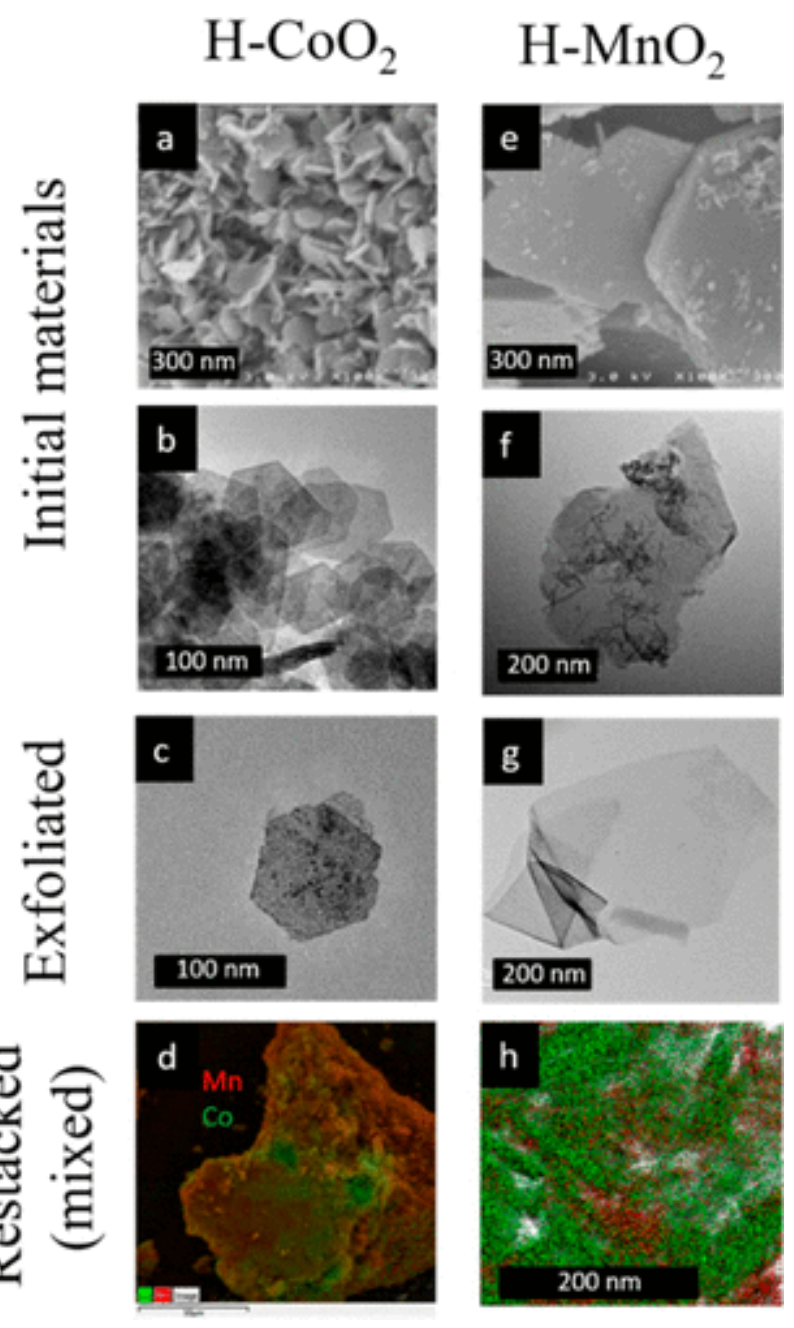

Figure 4. (a) SEM image and (b) TEM image of pristine $\mathrm{H}-\mathrm{CoO}_{2}$. (c) TEM image of exfoliated H-CoO 2. (d) SEM-EDS image of restacked mixed material with 50\% of Mn and 50\% of Co (Mn in red and Co in green). (e) SEM and (f) TEM image of pristine $\mathrm{H}-\mathrm{MnO}_{2}$. (g, $\mathrm{f}$ ) TEM image of exfoliated $\mathrm{H}-\mathrm{MnO}_{2}$. (h) TEM-EDS image of restacked mixed material with $50 \%$ of $\mathrm{Mn}$ and $50 \%$ of $\mathrm{Co}$ (Mn in red and Co in green). 


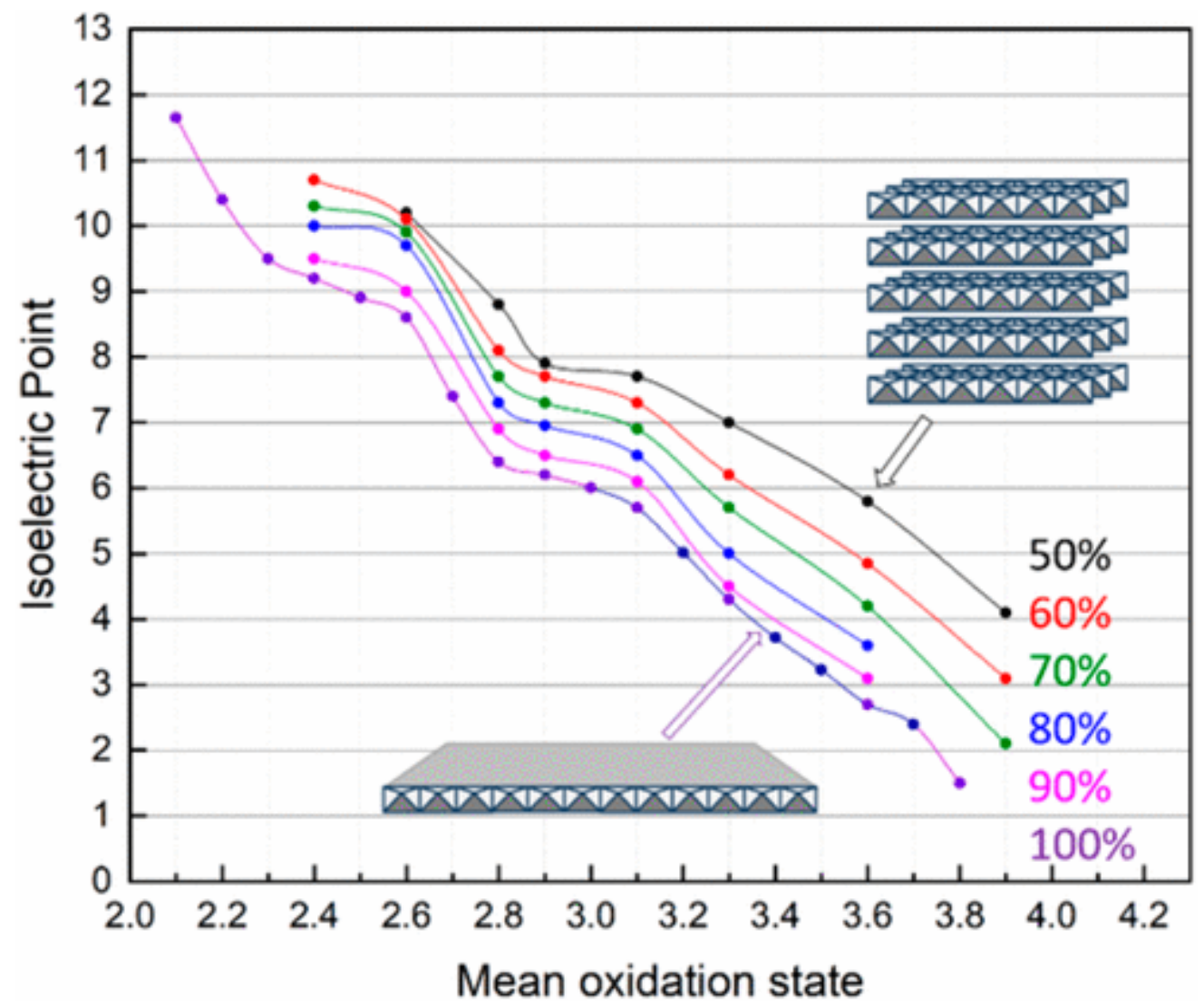

Figure 5. Theoretical IEP calculations depending on the mean oxidation state of the metal ion, for various basal area percentage over total surface area in the slabs.

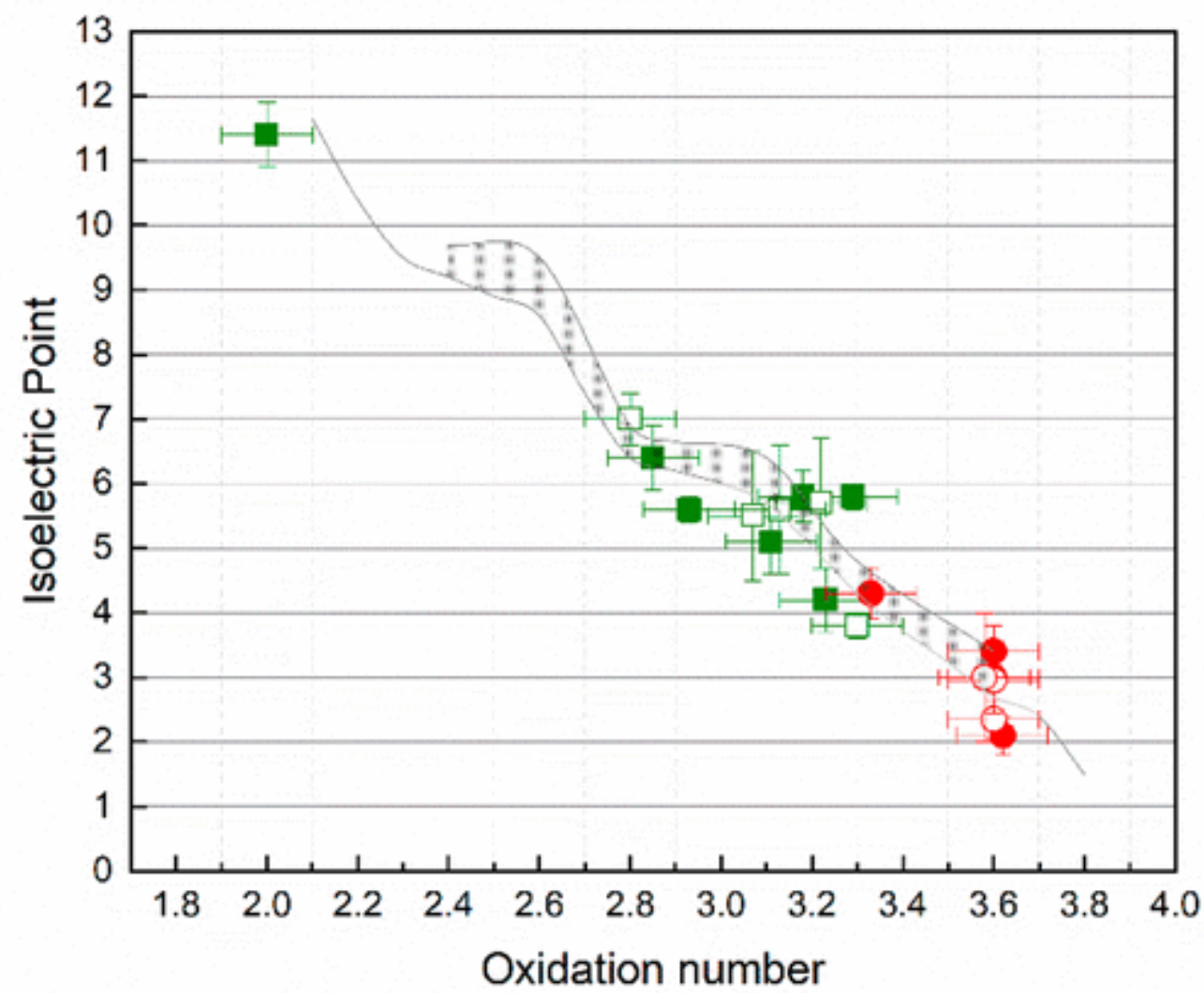

Figure 6. Experimental values of IEP depending on the mean oxidation state of metal ions in the pristine materials $\left(\bullet \mathrm{H}-\mathrm{CoO}_{2}, \bullet \mathrm{H}-\mathrm{MnO}_{2}\right)$ and exfoliated ones $\left(\square\right.$ ex $\mathrm{H}-\mathrm{CoO}_{2}$, ० ex $\left.\mathrm{H}-\mathrm{MnO}_{2}\right)$. They are compared with IEP values 
calculated with basal area percentage (dashed area) comprised between $85 \%$ and $100 \%$.

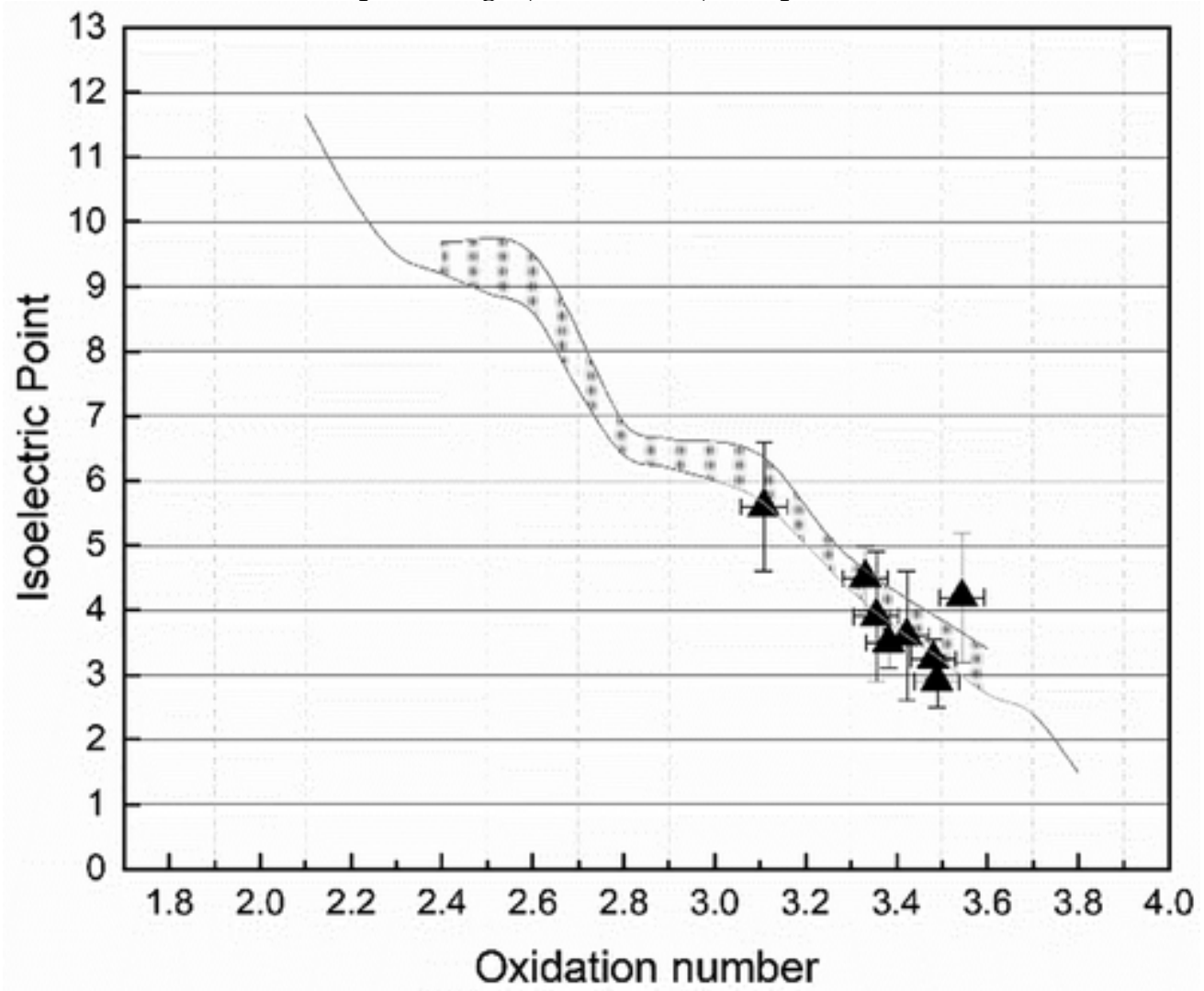

Figure 7. Variation of IEP values as a function of the mean oxidation state of metal ions in mixed Mn:Co restacked material. This oxidation state is obtained by linear combination of that of $\mathrm{Mn}$ and $\mathrm{Co}$ in the initial materials, taking into account the Mn:Co ratio of the restacked material. 